\section{Pioneering Advanced Surface Studies}

\section{HEWLETT-PACKARD EUROPHYSICS PRIZE}

Gerhard Ertl was appointed in 1986 Director of the Fritz-Haber-Institut der Max-PlanckGesellschaft, Faradayweg 4-6, W-1000 Berlin and Honorary Professor at Berlin's Free

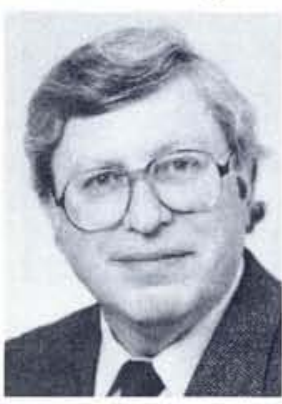
and Technical Universities. He received his Diploma in Physics from the $T U$ Stuttgart and his doctorate from the TU Munich in 1965, where he remained on the research staff until becoming Professor and Director of the university's Institute for Physical Chemistry in 1973. He has been a Visiting Professor at Caltech and at the Universities of California and Wisconsin in the USA. Professor Ertl co-edits Surf. Sci. Reports, Z. Phys. Chem. N.F. and the Springer Series in Surface Science and serves on the Editorial Boards of eight other journals. His awards include the American Catalysis Society's 1979 P.H. Emmett Award, the 1979 E.W. Müller Award, the German Chemical Society's 1987 Liebig Medal, and the German Science Foundation's 1991 Leibniz Prize.

Harald Ibach, Director of the Institute of Surface Research and Vacuum Physics, For-

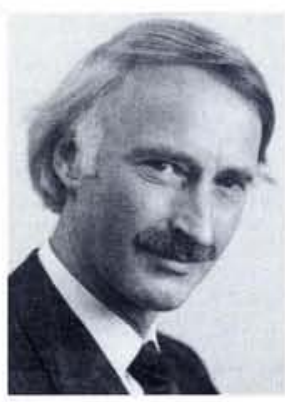
schungszentrums (KFA) Jülich, Postfach 1913, W-5170 Jülich, Germany, since 1974, was appointed in 1975, jointly with the KFA Professor of Physics at the RWTH, Aachen. He studied at the RWTH, receiving his Dr. rer. nat. in 1968, where he remained as a research assistant until spending 1973 on the research staff of the IBM Bell Laboratories, NJ, USA. Professor lbach has been a visiting scientist at universities in the USA on three occasions, a Co-Editor of Appl. Phys. and an Associate Editor of Phys. Rev. Lett. He was the University of California's 1989 Regent's Professor, and won the University of Wisconsin's 1982 E.W. Müller Award and the American Vacuum Society's $1986 \mathrm{Me}$ dard W. Welch Award.

J. Peter Toennies, Director of the MaxPlanck-Institut für Strömungsforschung, Bunsenstrasse 10, W-3400 Göttingen, and Associate Professor in the Physics De-

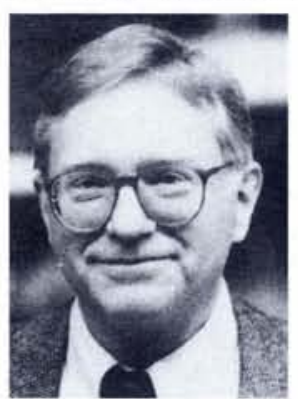
partment, University of Göttingen, since 1971, is also an Honorary Professor at the University of Bonn. He received his first degree from Amherst College, MA, USA, and his Ph.D. in chemistry from Brown University, RI, USA, in 1957. He then joined Bonn University's Physics Department, being awarded his Habilitation in 1965 and holding Visiting Professorships at the University of Florida, USA, and Chengdu University, PRC. Professor Toennies has been an active member of EPS, serving on the Atomic and Molecular Physics Board (1972-8), on the Finance Committee (1981-3) and as an IOM Council Delegate (1978-81). He co-authored Chemical Reactions in Shock Waves, belongs to the Advisory Boards of Chem. Phys. and of Perspectives in Condensed Matter Physics, and co-edits the Springer Series in Chemical Physics. He won the Czechoslovak Academy of Science's 1991 Heyrovsky Gold Medal.

\title{
CALL FOR NOMINATIONS
}

\section{Hewlett-Packard Europhysics Prize}

The Selection Committee for the Hewlett-Packard Europhysics Prize invites nominations for the 1993 award. The Prize is given for an outstanding contribution to condensed matter physics within the previous five years, with the potential for leading advances in the fields of electronic, electrical or materials engineering. Nominations may be submitted by EPS members as individuals or as representatives of a Division, Section or Group.

Previous winners have been: $\mathrm{H}$. Ibach, G. Ertl and J.P. Toennies (1992); D. Jérome and K. Bechgaard (1991); R. Car and M. Parrinello (1990). To maintain the extremely high standard, it is necessary that the Committee receive proposals which represent the breadth and strength of European condensed matter physics. We would be grate-
The 1992 Hewlett-Packard Europhysics Prize for outstanding achievements in condensed matter physics has been awarded jointly to Professors G. Ertl (Fritz-Haber-Institut, Berlin) H. Ibach (Forschungscentrum, Jülich) and J.P. Toennies (Max-Planck-Institut für Strömungsforschung, Göttingen) for pioneering studies of surface structures, dynamics and reactions through the development of novel experimental methods. The award ceremony will take place on 8 April 1992 during the 12 th General Conference of the Condensed Matter Division of EPS in Prague.

The prizewinners have similar profiles: each developed novel experimental techniques for studying solid surfaces and at the same time performed outstanding systematic applications to uncover new basic physics. Their research has not only increased our fundamental understanding of the properties of condensed matter, but has also contributed significantly to descriptions of complex technologically important phenomena where the properties of surfaces play a major rôle. The impact has so far been the greatest in the field of heterogeneous catalysis, but other areas ranging from tribology to micro-electronics also benefit

Professor Ertl has been for a long time been a world-wide leader in the experimental investigation of the structure and reactivity of metal surfaces. His systematic work led to a breakthrough in bridging the "pressure gap" between basic surface physics and heterogeneous catalysis, where the atomic scale details of an important catalytic surface reaction were described and understood for the first time. More recently, he has opened up a completely new subfield in surface physics concerned with mesoscopic scale surface structure. He has developed a new technique, scanning photoemission microscopy, and used it and simiIar techniques to study spatial and temporal self-organization on metal surfaces. His studies constitute some of the most beautiful experimental illustrations of these phenomena, including soliton waves.

Professors Ibach and Toennies have extended the two most powerful methods (electron energy loss spectroscopy and inelastic helium atom scattering, respectively) for studying vibrations at surfaces to a level of perfection which is completely in a class by itself. Vibrational spectroscopy is presently the most direct way of probing inter-atomic interactions at surfaces - interactions which provide the basis for most of the surface phenomena that are studied, ranging from surface structures to phase transitions, diffusion and chemical reactions. Owing to these developments we have, finally and within the last two years, a description of surface phonons which should develop into one which is of the same quality as for the bulk even though surface phonons are much more complex. Meanwhile, electron energy loss spectroscopy remains the most important tool for studying adsorbate vibrations at surfaces.

\section{J. Nørskov \\ Technical University, Lyngby}

P. Wyder

Chairman, Selection Committee 